\title{
Integration Magnifies Locational Subsidy Effects and Cross-Border Ownership?
}

Wataru Johdo

Tezukayama University, Nara, Japan

\begin{abstract}
This paper investigates the welfare effects of an increase in location subsidy by constructing a general equilibrium linear space model, including transport costs and the cross-border ownership of equities. We assume a market structure with monopolistic competition in which entry is restricted and where fixed costs are not necessary. These model characteristics allow us to obtain the analytical welfare effects that have yet to be examined. We find that the subsidy increase improves (reduces) the domestic (foreign) welfare, regardless of the size of transport costs. However, closer economic integration magnifies the impacts of the location subsidy.
\end{abstract}

JEL Classifications: F15, F20, H20, L11

Key words: Location Subsidy, Cross-border Ownership, Economic Integration, Welfare

\footnotetext{
* Corresponding Author: Wataru Johdo; Faculty of Economics, Tezukayama University, 7-1-1 Tezukayama, Nara, 631-8501, Japan; Tel: +81 742489380, Fax: +81 742464994, E-mail: johdo@tezukayama-u.ac.jp. 


\section{Introduction}

In recent years, developed countries have been placed under pressure as a result of increased worldwide firm mobility, which has made it possible for domestic firms to move to foreign countries. The governments in these countries have responded to this challenge with various policies, including location subsidies or reductions in corporate taxation. ${ }^{1}$ The principal intention of these policies is to help the recovery of the domestic economy and alleviate domestic unemployment by attracting foreign firms. Given the ongoing rapid growth of international firm mobility, these expectations of increasing use of location subsidies and associated policies are common in the business media. We should not overlook the fact that cross-border ownership of corporate stock - involving domestic and foreign ownership of a firm, with profits repatriated to each type of owner - has recently increased in developed countries. ${ }^{2}$ This is significant because under the cross-border ownership of corporate stock, an increase in location subsidy or a reduction in corporate tax in one country shifts some income to foreign countries, along with the repatriation of rent income to foreign investors. This implies that, if the negative effect of the income transfer offsets the benefit from inflows of foreign firms, the national income of the country that pays the subsidies may decrease. Therefore, if the aim of an increase in location subsidy (or a reduction in corporate tax) by one country is to attract foreign firms to the domestic country to increase national income, it is necessary for policymakers to take both cross-border ownership and the income transfer of the location subsidy (or corporate tax reduction) into consideration.

There are two relevant strands of literature on how location subsidies (or location taxes) affect the international distribution of firms (or mobile capital) and welfare. First, using a neoclassical model of tax competition, where governments provide a public good but trade costs are excluded (the so-called basic tax competition model), Wilson (1986) and Zodrow and Mieszkowski (1986) showed that increasing capital mobility always causes governments to set capital taxes inefficiently low. However, because they begin with the assumption of a closed economy, composed of identical local governments, they cannot consider the impact of enterprise relocation on another country. Recently, enterprises have actively invested across national borders. It is,

\footnotetext{
' In fact, in the past two decades, most Organization for Economic Co-operation and Development (OECD) economies have lowered their corporate taxes to attract foreign firms. See, for example, Haufler (1999) and Bretschger and Hettich (2002).

${ }^{2}$ Wojcik (2002) provides evidence regarding the significance of cross-border ownership in 16 European countries. Egger et al. (2010) and Forbes (2010) include additional recent evidence for cross-border ownership in developed countries.
} 
therefore, appropriate that a two-country (or two-region) model should be adopted to examine the impact of enterprise relocation between economic powers. In addition, as the above analyses are simplified by the assumption of freely traded goods (that is, transportation costs are assumed to be zero), the question remains as to how deeper economic integration affects the extent of the impacts of a tax reduction. Further, as these authors overlooked the cross-border ownership of capital stocks, their contribution does not provide any insight into the interaction between the international income redistribution effect of a distorting tax and national income.

The second strand of literature is the new economic geography (NEG) literature on tax competition. This literature includes Ludema and Wooton (2000), Andersson and Forslid (2003), Baldwin and Krugman (2004) and Borck and Pflüger (2006). In the NEG literature on tax competition, these authors showed that closer trade integration causes mobile factors to agglomerate in one of two countries, inducing the country in which the factors are concentrated to set a higher tax rate on mobile factors (within certain limits) without jeopardizing the factor concentration. As stated above, a great deal of the research effort has been focused on tax competition in the NEG literature. What seems to be lacking, however, is the analysis of cross-border ownership of firms. Indeed, the above models often assume two types of workers mobile "entrepreneurs" and immobile "workers." In these models, the incomes of entrepreneurs and workers are treated separately, the government imposes a head tax on mobile entrepreneurs only, and the government distributes all tax revenues to domestic immobile workers. Consequently, all tax revenues from the head tax circulate within the same country. Therefore, in these models, there is no analysis of the interaction between the international income redistribution effect of an increase in the distorting tax and the impact on the national income in each country resulting from the cross-border ownership of firms.

One possible exception in the NEG literature is Kind, Midelfart, and Schjelderup (2000), who investigated how taxes on mobile capital were set if an industry was concentrated in a single location, using a two-country model that incorporated the crossborder ownership of capital. The authors showed that in the presence of a cross-border ownership of capital, firms could earn greater agglomeration rents in the host country. Consequently, the government in that region could charge a higher tax rate on capital than that of the peripheral region as long as the rents outweigh the tax differential. ${ }^{3}$

\footnotetext{
${ }^{3}$ The other relevant exception is Ottaviano and van Ypersele (2005), where a source-based tax influences mobile capital. In their model, given the fixed location of the owners of capital, if the country that taxes capital also imports mobile capital from the foreign
} 
This implies that the outcome of tax competition is the same as that found in the NEG literature on tax competition even under the cross-border ownership of capital. However, the findings of Kind, Midelfart, and Schjelderup regarding the outcomes on capital tax competition rely heavily on numerical simulations.

The purpose of this paper is to analyze the results of an increase in location subsidy without depending on numerical simulation. For this purpose, we propose a two-country general equilibrium model, including the international relocation of firms, transport costs, and cross-border ownership of equities.

There are some crucial differences between our model and that of Kind, Midelfart, and Schjelderup(2000). The important point to note is that our paper assumes a linear segment for the spatial division of firms $(n \in[0,1])$, where firms in the interval $[0, n]$ are located in the home country, and the remaining firms $[n, 1)$ are located in the foreign country. The reason why we assume a linear segment is for tractability, so that we can solve the model analytically for the spatial division of firms even with the exclusion of fixed costs. ${ }^{4}$ This feature is uncommon in the literature on economic geography because of this exclusion of fixed costs. If we were to delete the linear space from our model in order to determine the number of firms in each country, we would have to assume fixed costs in the production sector. However, if we introduce fixed costs into our model, the profit of each country becomes zero in equilibrium through the freeentry conditions. This means that it becomes impossible to determine the international distribution of firms through profit arbitration between the two countries (i.e., $\Pi(h)$ $=\Pi^{*}(f)>0$, where $\Pi(h)$ and $\Pi^{*}(f)$ are the profit flows of the home- and foreignlocated firms) because the free-entry conditions, $\Pi(h)=0$ and $\Pi^{*}(f)=0$, always hold. In addition, under positive fixed costs and because of the zero-profit conditions in equilibrium, the rent redistribution effect, which can play an important role in determining how an increase in location subsidy affects national income and welfare in each country, disappears from our model. Therefore, in our model, the existence of positive pure profits and the profit-equality condition are indispensable for determining the international distribution of firms in each country.

Intuitively, under the profit-equality condition, the international relocation mechanism that occurs through the location subsidy increase is as follows. First, an increase in $\tau$ (the location subsidy) leads to an increase in the relative profit of firms

\footnotetext{
country, then part of the tax burden is transferred to the foreign owners of the capital.

${ }^{4}$ As stated above, we normalize the number of firms in the world to unity in our model. Therefore, it is not necessary to assume fixed costs and the zero-profit condition to determine the total number of firms.
} 
located in the home country (that is, $(1+\tau) \Pi(h)>\Pi^{*}(f)$ ), which then leads to the relocation of some firms leaving the foreign country and shifting to the home country. This firm relocation continues until all positive pure profits equalize worldwide (that is, $\left.[1+\tau] \Pi[h]=\Pi^{*}[f]\right)$. Therefore, in our model, the international relocation of firms always adjusts completely, owing to the profit-equality condition.

Moreover, the NEG literature has largely focused on the mechanism under which the agglomeration, which results from the exogenous lowering of fixed trade costs, opens up the possibility of a race to the top in tax rates. However, it leaves unanswered an important practical question; that is, why do most OECD countries have an incentive to reduce their corporate tax, a situation somewhat consistent with the current state of affairs in both Japan and the US, given deeper trade integration? ${ }^{5}$ Our model, by contrast, has different welfare effects from those obtained in the NEG literature. We conclude that the location subsidy increase always improves (reduces) the domestic (foreign) welfare regardless of the level of trade costs. Thus, the outcomes of our paper can explain why most OECD countries have an incentive to reduce their corporate tax under the recent deeper trade integration.

The remainder of this paper is structured as follows. Section II outlines the features of the model. Section III describes the equilibrium. Section IV presents the impact of a changing location subsidy on international industrial location and consumption. Section $\mathrm{V}$ examines the welfare effects of a location subsidy and then shows how deeper economic integration affects the welfare effects. The final section concludes the paper.

\section{The Model}

We assume a two-country world economy, with a home and a foreign country. The models for the home and foreign countries are the same, and an asterisk is used to denote foreign variables. There are two types of goods: horizontally differentiated goods and a single homogeneous good. The differentiated goods are subject to a monopolistically competitive market structure, whereas the market for the homogeneous good is perfectly competitive. Both the differentiated goods and the homogeneous good are assumed to be produced using a constant-returns technology that requires labor as

\footnotetext{
5 Based on a panel data from 1967 to 1996 for 12 OECD countries, Bretschger and Hettich (2005) find that globalization has a negative effect on capital tax rates.
} 
the only input. The market for labor is perfectly competitive and perfect labor mobility is assumed within each country. The homogeneous good is assumed to be traded freely, whereas trade in the differentiated goods incurs transport costs. Monopolistically competitive firms exist continuously in the world in the $[0,1]$ range, where each firm produces a single differentiated product. Monopolistically competitive firms are mobile across countries, but their owners are not. Hence, all profit flows are distributed to the immobile owners according to the holding shares. In addition, firms in the interval $(0, n)$ are located in the home country, and the remaining $(n, 1]$ firms are located in the foreign country where $n$ is endogenous. Therefore, $n$ and $1-n$ measures the home and foreign country's share of firms respectively. Meanwhile, homogeneous goods producers are immobile across countries. The size of the world population is normalized to unity; therefore, $s+s^{*}=1$ where $s$ measures the relative size of the home country and each household owns one unit of labor.

Preferences are defined over a homogeneous good, named $Y$, and over differentiated goods, named $C$. In this paper, the preferences of household $i \in(0, s)$ in the home country are represented by the following utility function: ${ }^{6}$

$$
U^{i}=\alpha \ln C^{i}+(1-\alpha) \ln Y^{i}
$$

where $\alpha$ is the expenditure share on differentiated goods. Here, we take the price of the homogeneous good as the numéraire. Hence, the price is normalized to one. In addition, in equation (1) the consumption index $C^{i}$ is defined as follows:

$$
C^{i}=\left(\int_{0}^{n} C^{i}(j)^{(\theta-1) / \theta} d j+\int_{\mathrm{n}}^{1} C^{i *}(j)^{(\theta-1) / \theta} d j\right)^{\theta /(\theta-1)}
$$

where $\theta>1$ measures the elasticity of substitution between any two differentiated goods and $C^{i}(j)$ is the consumption of good $j$ for household $i$. We assume iceberg transport costs in shipping the differentiated goods between countries. Specifically, $t(t$ $\geq 1$ ) units of a differentiated good have to be shipped from one country to the other for one unit to arrive at its destination. The consumption price index is defined as:

$$
P=\left(\int_{0}^{\mathrm{n}} P(j)^{1-\theta} d j+\int_{\mathrm{n}}^{1}\left(t P^{*}(j)\right)^{1-\theta} d j\right)^{1 /(1-\theta)}
$$

\footnotetext{
${ }^{6}$ In what follows, we focus mainly on the description of the home country because the foreign country is described analogously.
} 
where $P(j)$ is the price of differentiated goods produced in $j$. The value of expenditure for household $i$ is $E^{i}$ defined as follows;

$$
E^{i}=\int_{0}^{\mathrm{n}} P(j) C^{i}(j) d j+\int_{\mathrm{n}}^{1} t P^{*}(j) C^{i}(j) d j+Y^{i}
$$

We assume that every household supplies one unit of labor to domestic firms at the domestic wage rate and receives profits from all firms equally under the cross-border ownership of equities. After which, the household budget constraint can be written as:

$$
E^{i}=W+\int_{0}^{n} \Pi(j) d j+\int_{n}^{1} \Pi^{*}(j) d j
$$

where $W$ denotes the nominal wage rate and $\Pi(j)\left(\Pi^{*}(j)\right)$ is the nominal profit flow of firm $j$ located at home (abroad).

Households in the home (foreign) country maximize equation (1) subject to equation (4) by allocating $C^{i}(j)$ and $Y^{i}$ optimally. This problem yields:

$$
\begin{gathered}
C^{i}(h)=\left(\frac{P(h)}{P}\right)^{-\theta}\left(\frac{\alpha E^{i}}{P}\right) \\
C^{i}(f)=\left(\frac{t P^{*}(f)}{P}\right)^{-\theta}\left(\frac{\alpha E^{i}}{P}\right) \\
Y^{i}=(1-\alpha) E^{i}
\end{gathered}
$$

Here, we define $\psi \equiv t^{1-\theta} \in(0,1)$ as the degree of trade openness for convenience, where $\psi$ equalizes to one under free trade and it also approaches zero when trade is extremely costly. The households are supposed to be symmetric, so we can delete the superscript $i$ from $E^{i}$. Aggregating the demands in equations (6a) and (6b) across all households worldwide yields the following market clearing condition for any differentiated product of the domestic located firms: ${ }^{8}$

$$
x(h)=s\left(\frac{P(h)}{P}\right)^{-\theta}\left(\frac{\alpha E}{P}\right)+s^{*} \psi\left(\frac{P(h)}{P^{*}}\right)^{-\theta}\left(\frac{\alpha E^{*}}{P^{*}}\right)
$$

\footnotetext{
${ }^{7}$ In a related two-country monopolistic trade model, Corsetti et al. (2005) also posit that each home and foreign household receives an equal share of profits of all firms as shown in Equation 5.

${ }^{8}$ We have used the index $h$ to denote the symmetric values within the home country, and we have used the index $f$ for the foreign country.
} 
Similarly, for any product $(f)$ of the foreign located firms, we obtain:

$$
x(f)^{*}=s \psi\left(\frac{P^{*}(f)}{P}\right)^{-\theta}\left(\frac{\alpha E}{P}\right)+s^{*}\left(\frac{P^{*}(f)}{P^{*}}\right)^{-\theta}\left(\frac{\alpha E^{*}}{P^{*}}\right)
$$

In the monopolistic goods sector, each firm has some monopoly of power over pricing and one unit of labor is required to produce one unit of a variety. Because home-located firm or $h$ hires labor domestically, given $W, P, E, E$, and $n$, and subject to equation (7), $h$ faces the following profit-maximization problem:

$$
\max _{P(h)} \Pi(h)=(P(h)-W) x(h)
$$

By substituting $x(h)$ from equation (7) into the firm's nominal profit $\Pi(h)$ and then differentiating the resulting equation with respect to $P(h)$, we obtain the following markup price:

$$
P(h)=\left(\frac{\theta}{\theta-1}\right) W
$$

Turning to the homogeneous good sector, one unit of labor is required to produce one unit of the homogeneous good. In addition, we assume that a portion of the production of the homogeneous good is active in both countries. Hence, the factor-price equalization $W=W^{*}=1$ is ensured because of the free trade of the homogeneous good. Therefore, from equation (10), we obtain:

$$
P(h)=P(f)^{*}=\left(\frac{\theta}{\theta-1}\right) \equiv P_{w}
$$

Substituting equations (7) and (10) and those of foreign counterparts into the profit flows of the home- and foreign-located firms, $\Pi(h)$ and $\Pi(f)^{*}$, respectively, we obtain:

$$
\begin{aligned}
\Pi(h) & =\left(\frac{1}{\theta-1}\right) x(h) \\
\Pi(f)^{*} & =\left(\frac{1}{\theta-1}\right) x(f)^{*}
\end{aligned}
$$

The model assumes that firms do not face any relocation costs so that it does not 
take any time to relocate to another country. For a firm to be indifferent between home and foreign locations after location arbitrage, returns from the two locations must be equalized as follows:

$$
\Pi(h)=\Pi(f)^{*}
$$

Here, substituting equation (11) into equation (3) and the counterpart of the foreign country, respectively, we obtain $P^{1-\theta}=[n+\psi(1-n)] P_{w}^{1-\theta}$ and $P^{* 1-\theta}=[\psi n+1-n] P_{w}^{1-\theta}$. In addition, substituting these equations and equation (11) into equations (8) and (9), respectively, we obtain:

$$
\begin{aligned}
& x(h)=\alpha\left(\frac{\theta-1}{\theta}\right)\left[\frac{s E}{n+(1-n) \psi}+\frac{\psi s^{*} E^{*}}{(1-n)+\psi n}\right] \\
& x(f)^{*}=\alpha\left(\frac{\theta-1}{\theta}\right)\left[\frac{\psi s E}{n+(1-n) \psi}+\frac{s^{*} E^{*}}{(1-n)+\psi n}\right]
\end{aligned}
$$

Meanwhile, substituting equations (12a) and (12b) into equation (13), we obtain $x(h)=x(f)^{*}$. Therefore, if we substitute equations (14) and (15) into $x(h)=x(f)^{*}$, we obtain:

$$
n=\frac{s E-\psi s^{*} E^{*}}{(1-\psi)\left(s E+s^{*} E^{*}\right)}
$$

Furthermore, substituting equation (16) into equation (14) and considering $x(h)=$ $x(f)^{*}$, we obtain:

$$
x(h)=x(f)^{*}=\alpha\left(\frac{\theta-1}{\theta}\right)\left(s E+s^{*} E^{*}\right)=x
$$

Finally, substituting equations (12a) and (12b) into equation (13) and considering equation (17), we obtain the following equilibrium income levels for each country:

\footnotetext{
${ }^{9}$ In the direct foreign investment literature (e.g., Wang and Tsai, 1996; Yoshida, 1996), locations take the form of financial portfolio investment. The distribution of foreign direct locations is then determined so as to equalize the net return on domestic and foreign investments for capital owners.
} 


$$
\Pi(h)=\Pi(f)^{*}=\left(\frac{\alpha}{\theta}\right)\left(s E+s^{*} E^{*}\right)
$$

\section{Market Equilibrium}

Substituting $W=W^{*}=1$ and equation (18) into equation (5) and due to $E^{i}=E$, we obtain the following equilibrium income levels for each country:

$$
E=E^{*}=\frac{\theta}{\theta-\alpha}
$$

In addition, substituting equation (19) into equation (18), we obtain:

$$
\Pi(h)=\Pi(f)^{*}=\left(\frac{\alpha}{\theta-\alpha}\right)
$$

Furthermore, substituting equation (19) into (16) gives the equilibrium distribution of firms between countries:

$$
n={\frac{s(1+\psi)-\psi^{10}}{1-\psi}}^{1-\psi}
$$

From equation (21), we find the parametric condition required for $n$ to be between 0 and 1 (an interior equilibrium) as follows:

$$
\frac{\psi}{1+\psi}<s<\frac{1}{1+\psi}
$$

In what follows, we assume that equation (22) is valid, so that both countries produce the differentiated products.

\footnotetext{
${ }^{10}$ Based from Equation 21, the symmetric equilibrium $n=1 / 2$ is always a solution when $s=1 / 2$. Equation 21 also shows that the conventional home-market effect is observed as in Helpman and Krugman (1985). In the literature on home-market effects, Huang and Huang (2011) extend the model of Helpman and Krugman (1985) by considering the technology difference between countries and find that the opposite effect of the home-market effect can emerge.
} 


\section{The Effects of Location Subsidy}

We assume that the home government imposes a lump sum tax on domestic households and pays location subsidy to domestically located firms. The profit-equality condition in the presence of location subsidy is as follows:

$$
(1+\tau) \Pi(h)=\Pi(f)^{*},
$$

where

$$
\begin{aligned}
& \Pi(h)=\left(\frac{\alpha}{\theta}\right)\left[\frac{s E}{n+(1-n) \psi}+\frac{\psi s^{*} E^{*}}{(1-n)+\psi n}\right] \\
& \Pi(f)^{*}=\left(\frac{\alpha}{\theta}\right)\left[\frac{\psi s E}{n+(1-n) \psi}+\frac{s^{*} E^{*}}{(1-n)+\psi n}\right]
\end{aligned}
$$

and $\tau$ is the rate of location subsidy. ${ }^{11}$ The household budget constraints per capita for each country in the presence of the location subsidy are then: ${ }^{12}$

$$
\begin{gathered}
E=W+\left(\int_{0}^{n} \Pi(j) d j+\int_{n}^{1} \Pi^{*}(j) d j\right)-\left(\frac{1-s}{s}\right) \int_{0}^{n} \tau \Pi(j) d j \\
E^{*}=W^{*}+\left(\int_{0}^{n} \Pi(j) d j+\int_{n}^{1} \Pi^{*}(j) d j\right)+\int_{0}^{n} \tau \Pi(j) d j
\end{gathered}
$$

The first term in the above equations is labor income, the second denotes rent income, and the third denotes the income transfer from home to foreign country through the location subsidy. Given that the last term represents the subsidy transfer to foreign country from home-located individuals, the increase in $\tau$ leads the government in the home country to shift part of the subsidy from its own country to foreign countries in the form of rent income repatriation to foreign households. Henceforth we refer to this as the "rent redistribution effect" of the increase in $\tau$. Thus, we obtain the following lemma.

\footnotetext{
${ }^{11}$ If $\tau$ is negative, we can interpret it as the rate of profit tax (or corporation tax).

${ }^{12}$ Note that an increase in the subsidy rate is equivalent to a decrease in the corporate tax rate.
} 
Lemma 1: The rent redistribution effect of location subsidy in one country is always negative for the total income of its economy and positive for the foreign country.

Substituting $W=W^{*}=1$ into equations (26) and (27), respectively, and aggregating the resulting equations, we obtain:

$$
\begin{gathered}
s E=s+s\left(\frac{\alpha}{\theta-\alpha}\right)-(1-s) \tau n \Pi(h), \\
s^{*} E^{*}=s^{*}+s^{*}\left(\frac{\alpha}{\theta-\alpha}\right)+(1-s) \tau n \Pi(h) .
\end{gathered}
$$

From equations (23), (28), and (29), the impacts of an increase in $\tau$ on $n$ and $s E$ and $s^{*} E^{*}$ evaluated at $\tau=0$ are then:

$$
\begin{gathered}
\left.\frac{d n}{d \tau}\right|_{\tau=0}=\frac{(1-s)(1+\psi)[s(\theta-\alpha)(1+\psi)+\alpha \psi]}{\theta(1-\psi)^{2}}>0, \\
\left.\frac{d(s E)}{d \tau}\right|_{\tau=0}=-s^{*}\left(\frac{\alpha}{\theta-\alpha}\right)\left(\frac{s(1+\psi)-\psi}{1-\psi}\right)<0, \\
\left.\frac{d\left(s^{*} E^{*}\right)}{d \tau}\right|_{\tau=0}=s^{*}\left(\frac{\alpha}{\theta-\alpha}\right)\left(\frac{s(1+\psi)-\psi}{1-\psi}\right)>0 .
\end{gathered}
$$

The result in equation (30) shows that an increase in $\tau$ leads to the relocation of some firms away from foreign country to home country $(\mathrm{d} n / \mathrm{d} \tau>0)$. This is because an increase in $\tau$ leads to an increase in the relative profit of firms located in the home country, which results to the relocation of some firms away from the foreign country to the home country. In addition, equation (30) tells us that the larger $\psi$ is, the greater the movement of firms is. The two results in equations (31) and (32) show that an increase in $\tau$ leads to a decrease in the aggregate income of the home country $s E$ and an increase in $s^{*} E^{*}$. This is because an increase in $\tau$ decreases profit income in the home country and increases that of the foreign country through the rent redistribution effect (see Lemma 1).

We now examine the impacts of location subsidy on the price index of each country. Differentiating equation (3) and the counterpart of the foreign country with respect to $\tau$, and evaluating the signs of the resulting equations at $\tau=0$, we obtain: 


$$
\begin{aligned}
& \left.\frac{d P}{d \tau}\right|_{\tau=0}=-\frac{s^{*}(1+\psi)[s(1+\psi)]^{\theta /(1-\theta)}[s(\theta-\alpha)(1+\psi)+\alpha \psi]}{(\theta-1)^{2}(1-\psi)}<0, \\
& \left.\frac{d P^{*}}{d \tau}\right|_{\tau=0}=\frac{s^{*}(1+\psi)\left[s^{*}(1+\psi)\right]^{\theta /(1-\theta)}[s(\theta-\alpha)(1+\psi)+\alpha \psi]}{(\theta-1)^{2}(1-\psi)}>0 .
\end{aligned}
$$

The result in equation (33) shows that an increase in location subsidy in the home country lowers the price index in that country. Conversely, from equation (34), the location subsidy increases the price index in the foreign country. We intuitively explain these results as follows. From equation (11) and recalling that $t(t \geq 1)$ units of a differentiated good have to be shipped from one country to the other for one unit to arrive at its destination, we obtain $t P^{*}(f)=t P(h) \geq P(h)$. This implies that the domestic prices of foreign differentiated goods $\left(=t P^{*}(f)\right)$ are always higher than the domestic prices of domestic differentiated goods $(=P(h))$. Therefore, a decrease of the share of $t P^{*}(f)$ (that is, $\left.(1-n) t P^{*}(f)\right)$ in the home price index $P$ through the relocation of firms from a foreign country to a home country $(\mathrm{d} n>0)$ is associated with a downward pressure in the domestic price index as shown in equation (33). Analogously, an increase in the share of home goods (or an increase of $n t P(h)$ ) in the foreign price index $P^{*}$ through the relocation of firms from a foreign country to a home country is associated with an upward pressure in the foreign price index as shown in equation (34). Henceforth, we refer to these as the "price index effect" of the increase in $\tau$. We also obtain the following lemma.

Lemma 2: The price index effect of an increase in $\tau$ is always positive for the real incomes of the country undertaking the location subsidy and negative for the real incomes of the foreign country.

Moreover, from equations (33) and (34), it is worthwhile to note that the degree of trade openness $(\psi)$ influences the magnitude of the price index effect. equation (33) shows that the magnitude of $d P /\left.d \tau\right|_{\tau=0}$ depends positively on the degree of trade openness $(\psi)$; that is, the larger the $\psi$ is, the greater the magnitude of $d P /\left.d \tau\right|_{\tau=0}$ is. This is because based from equation (30), the larger the $\psi$ is, the greater the movement of firms is.

Next, we examine the impacts of an increase in a home country's location subsidy on the consumption index of each country through the rent redistribution effect and 
the price index effect. Substituting equations (6a) and (6b) into equation (2) and differentiating the resulting equation with respect to $\tau$, we obtain:

$$
\left.\frac{d(s C)}{d \tau}\right|_{\tau=0}=\frac{\alpha s^{*}[s(1+\psi)]^{1 /(\theta-1)} \widetilde{\psi}}{\theta(\theta-\alpha)(1-\psi)}>0,
$$

where

$$
\widetilde{\psi}=s \theta(1-\alpha)(1+\psi)+\alpha \psi(\theta-1)+\alpha \psi
$$

Similarly, for the foreign country, we obtain:

$$
\left.\frac{d\left(s^{*} C^{*}\right)}{d \tau}\right|_{\tau=0}=-\frac{\alpha s^{*}\left[s^{*}(1+\psi)\right]^{1 /(\theta-1)} \widetilde{\psi}}{\theta(\theta-\alpha)(1-\psi)}<0 .
$$

An intuitive explanation of equation (35) is as follows. First, an increase in a home country's location subsidy has opposing effects on the consumption in that country. On the one hand, equation (31) shows that an increase in $t$ lowers the aggregate income of the home country $(s E)$ through the negative rent redistribution effect (see Lemma 1). On the other hand, an increase in $\tau$ raises the real income in the home country through the price index effect (see Lemma 2). Hence, we obtain the ambiguous effects of a marginal increase in $\tau$ on the consumption index in the home country. However, equation (35) illustrates that an increase in a home country's subsidy causes the positive price index effect to dominate the negative rent redistribution effect. This raises consumption in the home country. Conversely, for the foreign country's consumption index, the location subsidy lowers the foreign consumption index (equation (37)) as the opposite mechanism is at work.

Next, we examine the impacts of location subsidy on the consumption of the homogeneous goods of each country. Differentiating equation (6c) and the counterpart of the foreign country with respect to $\tau$ and considering equations (31) and (32), we obtain:

$$
\begin{gathered}
\left.\frac{d(s Y)}{d \tau}\right|_{\tau=0}=\left.(1-\alpha) \frac{d(s E)}{d \tau}\right|_{\tau=0}<0, \\
\left.\frac{d\left(s^{*} Y^{*}\right)}{d \tau}\right|_{\tau=0}=\left.(1-\alpha) \frac{d\left(s^{*} E^{*}\right)}{d \tau}\right|_{\tau=0}>0 .
\end{gathered}
$$


The two results in equations (38) and (39) show that an increase in $t$ leads to a decrease in $s Y$ and an increase in $s^{*} Y^{*}$. This is because an increase in $\tau$ lowers profit income in the home country and increases that in the foreign country through the rent redistribution effect (see Lemma 1).

\section{Welfare and Economic Integration}

We now consider the impact of an increase in a home country's location subsidy on the welfare of each country. The utilities of a household for each country are:

$$
\begin{aligned}
& U=\ln E+\left(\frac{\alpha}{\theta-1}\right) \ln (n+\psi(1-n))+\Delta, \\
& U^{*}=\ln E^{*}+\left(\frac{\alpha}{\theta-1}\right) \ln (\psi n+1-n)+\Delta,
\end{aligned}
$$

where

$$
\Delta \equiv \alpha \ln \alpha+(1-\alpha) \ln (1-\alpha)-\alpha \ln \left(\frac{\theta}{\theta-1}\right)
$$

Differentiating these with respect to $\tau$ yields:

$$
\begin{aligned}
& \frac{d U}{d \tau}=\frac{1}{E} \frac{d E}{d \tau}+\left(\frac{\alpha}{\theta-1}\right) \frac{1}{n+\psi(1-n)}(1-\psi) \frac{d n}{d \tau}, \\
& \frac{d U^{*}}{d \tau}=\frac{1}{E^{*}} \frac{d E^{*}}{d \tau}+\left(\frac{\alpha}{\theta-1}\right) \frac{1}{\psi n+1-n}(\psi-1) \frac{d n}{d \tau}
\end{aligned}
$$

As seen in equations (43) and (44), the first element on the right hand side reflects the rent redistribution effect of a location subsidy, and the second element reflects the price index effect through the international relocation of firms. Therefore, the net effect on the welfare of each country depends on the relative strengths of these pressures. In order to determine the relative strengths, we evaluate the results in equations (43) and (44) at $\tau=0$. Substituting equations (30) and (31) into equation (43) and evaluating the signs of the resulting expressions at $\tau=0$ yields: 


$$
\left.\frac{d(s U)}{d \tau}\right|_{\tau=0}=\frac{\alpha s^{*}[s(1+\psi)(1-\alpha)+\psi(\theta-1)+\alpha \psi]}{\theta(1-\psi)(\theta-1)}>0
$$

Similarly, substituting equations (30) and (32) into equation (44), we obtain:

$$
\left.\frac{d\left(s^{*} U^{*}\right)}{d \tau}\right|_{\tau=0}=-\frac{\alpha s^{*}[s(1+\psi)(1-\alpha)+\psi(\theta-1)+\alpha \psi]}{\theta(1-\psi)(\theta-1)}<0
$$

Therefore, we obtain the following proposition.

Proposition 1: An increase in the location subsidy in home country raises welfare in that country. At the same time, the subsidy lowers welfare in the foreign country.

The above results can be intuitively explained as follows. First, for the home country's welfare, based from $d E /\left.d \tau\right|_{\tau=0}<0$ in equation (31), and $d n /\left.d \tau\right|_{\tau=0}>0$ in equation (30), the first term of equation (43), is the negative rent redistribution effect, and the second term is the positive price index effect. Therefore, the net effect on the home country's welfare is ambiguous. However, from equation (45), the latter effect always dominates the former, so we obtain $d(s U) /\left.d \tau\right|_{\tau=0}>0$. Conversely, for a foreign country's welfare, the opposite mechanism is at work in equation (44). Therefore, based on equation (46), the negative price index effect always dominates the positive rent redistribution effect, so we obtain $d\left(s^{*} U^{*}\right) /\left.d \tau\right|_{\tau=0}<0$.

Next, we consider how the degree of economic integration affects the welfare effects of an increase in the location subsidy. equations (45) and (46) show that the welfare effects in each country, given an increase in $\tau$, are positively dependent on the magnitude of transport costs $(\psi)$. Thus, as $\psi$ becomes larger, the larger the welfare effects of a location subsidy become as well. We now come to the following proposition.

Proposition 2: Closer economic integration magnifies the welfare impacts of location subsidy.

Intuitively, as discussed in equation (33), the downward pressure in the price index caused by the inflow of firms becomes larger as the transport costs become lower, that is, the lower the transport costs are, the larger the price index effect is. This implies that as the transport costs become lower, the larger the impact of an increase in a home country's subsidy on the consumption index in the home country turns out as 
discussed in equation (35). Meanwhile, the utility of the average national household depends positively on the consumption index. Therefore, based from equation (45), the magnitude of $d(s U) /\left.d \tau\right|_{\tau=0}$ depends positively on the size of $\psi$. Similarly, based on equation (34), since the upward pressure in the price index caused by the outflow of firms becomes larger as the transport costs become lower, the magnitude of $d\left(s^{*} U^{*}\right) /$ $\left.d \tau\right|_{\tau=0}$ also depends positively on the size of $\psi$ (equation (46)).

\section{Concluding Remarks}

The NEG literature on tax competition has devoted enormous energy to the question of how agglomeration, which results from the lowering of trade costs, opens up the possibility of a race to the top in tax rates. However, the findings regarding the outcomes of capital tax competition rely heavily on numerical simulations. By contrast, this paper adopted a linear space model in order to obtain analytical results for an increase in the location subsidy. We have proposed a two-country, general equilibrium model, including a linear segment for the spatial division of firms, transport costs, and cross-border ownership of equities. Using this model, this paper shows not only how a location subsidy affects consumption and welfare in all countries but also how closer economic integration affects the welfare effects of an increase in the location subsidy. The main findings of our analysis prove that an increase in the location subsidy in the home country increases home welfare and decreases foreign welfare regardless of the size of trade costs, and that closer economic integration magnifies the welfare impacts of the location subsidy. It is noteworthy that our results are in contrast with the results derived in the NEG literature, where lower trade costs cause mobile factors to agglomerate in one of the two countries, inducing that country to set a higher tax rate on mobile factors. In addition, the above results suggest that a subsidy policy in the home country can have beggar-thy-neighbor effects, in the sense that it lowers the welfare of the foreign country. Finally, this has the following policy implications. If the aim of a given country's subsidy policy is to attract foreign-located firms and to increase welfare, then that country should increase its location subsidy regardless of the size of trade costs or the degree of economic integration. 


\section{References}

Andersson, F. and Forslid, R. (2003). Tax Competition and Economic Geography, Journal of Public Economic Theory, 5, 279-303.

Baldwin, R. and Krugman, P. (2004). Agglomeration, Integration and Tax Harmonization, European Economic Review, 48, 1-23.

Borck, R. and Pflüger, M. (2006). Agglomeration and Tax Competition, European Economic Review, 50, 647668.

Bretschger, L. and Hettich, F. (2002). Globalisation, Capital Mobility and Tax Competition: Theory and Evidence for OECD Countries, European Journal of Political Economy, 18, 695-716.

Bretschger, L. and Hettich, F. (2005). Globalization and International Tax Competition: Empirical Evidence Based on Effective Tax Rates, Journal of Economic Integration, 20, 530-542.

Corsetti, G., Martin, P. and Pesenti, P. (2005). Productivity, Terms of Trade, and the 'Home Market Effect', Journal of International Economics, 73, 99-127.

Egger, P., Eggert, W., Keuschnigg, C. and Winner, H. (2010). Corporate Taxation, Debt Financing and Foreign-Plant Ownership, European Economic Review, 54, 96-107.

Forbes, K. J. (2010). Why do Foreigners Invest in the United States?, European Economic Review, 80, 3-21.

Haufler, A. (1999). Prospects for Co-ordination of Corporate Taxation and the Taxation of Interest Income in the EU, Fiscal Studies, 20, 133-153.

Helpman, E. and Krugman, P. (1985). Market Structure and Foreign Trade. MIT Press, Cambridge.

Huang Y. Y. and Huang D. S. (2011). Technology Advantage and Home-market Effect: An Empirical Investigation, Journal of Economic Integration, 26, 81-109.

Kind, H. J., Midelfart, K. H. and Schjelderup, G. (2000). Competing for Capital in a 'Lumpy' World, Journal of Public Economics, 78, 253-274.

Ludema, R. D. and Wooton, L. (2000). Economic Geography and the Fiscal Effects of Regional Integration, Journal of International Economics, 52, 331-357.

Ottaviano, G. I. P. and van Ypersele, T. (2005). Market Size and Tax Competition, Journal of International Economics, 67, 25-46.

Wang, Y. T. and Tsai, P. L. (1996). The Welfare Impact of Foreign Direct Investment in an Economic Region, Journal of Economic Integration, 11, 33-46.

Wilson, J. (1986). A Theory of Interregional Tax Competition, Journal of Urban Economics, 19, 296-315.

Wojcik, D. (2002). Cross-Border Corporate Ownership and Capital Market Integration in Europe: Evidence from Portfolio and Industrial Holdings, Journal of Economic Geography, 2, 455-491.

Yoshida, S. C. (1996). The Global Welfare of Illegal Immigration in the Presence of Capital Mobility, Journal of Economic Integration, 11, 554-565.

Zodrow, R. and Mieszkowski, P. (1986). Pigou, Tiebout, Property Taxation, and the Underprovision of Local Public Goods, Journal of Urban Economics, 19, 356-370. 